\title{
Discusiones en torno a la necesidad de debatir la Defensa Nacional
}

\author{
Francisco De Santibañes ${ }^{1}$
}

En este breve ensayo, presentaré algunos comentarios que surgen de mi lectura del trabajo publicado por Sergio Eissa en el número 53 de la revista Relaciones Internacionales. Ante todo, quiero señalar el importante aporte que significa iniciar un debate sobre la Defensa Nacional, tarea que los argentinos nos debemos hace décadas.

\section{La Defensa Nacional}

Eissa comienza su artículo afirmando que la política de Defensa es junto a la política de Derechos Humanos y al mejoramiento de las relaciones con nuestros vecinos, una de las pocas áreas de gobierno en donde existe consenso desde el retorno de la democracia. Podemos decir entonces que esta es una política de Estado. Señala como ejemplo los siguientes consensos: "la supresión de las hipótesis de conflicto con los países vecinos, b) la conducción civil de la política de Defensa y c) la separación orgánica y funcional de la Defensa Nacional y la Seguridad Interior"

Si bien, estos consensos existen (con la posible excepción del último) creo que en la Argentina la Defensa debe ser considerada como una política de Estado negativa. Y esto es así porque aquellos temas que, como bien señala el autor, hacen a la esencia de la Defensa (industria militar, adquisiciones, despliegue territorial, formación de los militares, entre otros) han sido ignorados por nuestra clase dirigente. Como resultado de esto, hoy la Argentina probablemente sea el único Estado medianamente relevante, en términos económicos y políticos, que no cuenta con FFAA operativas. Podemos decir entonces que desde el retorno de la democracia una de nuestras políticas de Estado ha sido no tener un sistema de Defensa funcional.

No vale la pena entrar en detalles respecto a esta realidad (horas de vuelo, estado de los sitemas de armas, hundimiento del ARA San Juan, un presupuesto que no supera el $1 \%$ del $\mathrm{PBI}$, etc.) ya que entre los especialistas del área existe un amplio consenso respecto al estado actual de las Fuerzas Armadas. Las causas son varias. Los traumas

\footnotetext{
${ }^{1}$ Especialista en relaciones internacionales. Ha publicado diversos artículos sobre seguridad internacional y política exterior argentina en revistas académicas del país y del exterior. Asimismo es autor del libro "La Argentina y el Mundo: Claves para una Integración Exitosa" (Edicon, 2016). Actualmente es miembro del Comité Ejecutivo del Consejo Argentino para las Relaciones Internacionales (CARI).

Email : fdesantibanes@yahoo.com.ar
} 
producidos por la intervención de los militares en la política nacional, la derrota en la Guerra de Malvinas y la falta de actores en el área de Defensa con poder suficiente para influir en las disputas presupuestarias son sólo algunas. Otra causa es que la Defensa despierta poco interés entre los miembros de la clase dirigente argentina, tema que retomaremos más adelante.

Una primera pregunta a responder entonces, es si la Argentina necesita un sistema de Defensa. Eissa hace un muy buen trabajo al mencionar los principales motivos. El primero, es que vivimos en un sistema internacional en donde reina la incertidumbre. Esto significa que quienes hoy son nuestros alíados el día de mañana pueden convertirse en nuestros adversarios y viceversa. Asimismo, las sorpresas estratégicas puede cambiar en pocas horas el contexto de Seguridad Internacional (recordemos los atentados del 11 de Septiembre del 2001).

Ante este nivel de incertidumbre, los Estados racionales no tienen otra opción que prepararse para enfrentar una gran cantidad de escenarios, algunos de los cuales ponen en peligro la seguridad, el bienestar, las libertades individuales y la misma subsistencia del Estado. Por lo tanto, si aspiramos a ser un país "normal" nosotros también tenemos que prepararnos para estas situaciones, dándole por ejemplo a las FFAA los medios que necesitan para formar parte de este proceso.

Las FFAA, también juegan un rol importante como instrumento de Política Exterior. No es casualidad que todos los miembros permanentes del Consejo de Seguridad de Naciones Unidas sean potencias nucleares. Incluso en el caso de un país medio como el nuestro, la presencia militar puede respaldar ciertas políticas (como lo hizo la Argentina al enviar naves al bloqueo naval a Cuba en los años 60 y a Iraq en los años 90)

Por otro lado, la Política Exterior también influye sobre el tipo de FFAA que necesita un país. Si un Estado está en condiciones de mantener un alto grado de autonomía (ya que no enfrenta amenazas inmediatas a su seguridad que lo obliguen a buscar el apoyo de una gran potencia o porque no depende para su desarrollo económico de un país en particular) debería fomentar el desarrollo de tecnologías estratégicas y diversificar la cantidad de proveedores de armamento. Una pregunta que debemos hacernos es si la Argentina se encuentra en esta categoría.

Sin lugar a dudas, las FFAA pueden cumplir otro tipo de funciones, entre las que se encuentran: custodiar las fronteras, brindar un sentido de identidad a los ciudadanos a través del servicio militar, asistir a la población en tiempos de catástrofes o combatir el terrorismo, pero ninguna de éstas hacen a su esencia.

Hoy, por ejemplo, se debate la posibilidad de derogar el decreto 727/2006 que le impide a las FFAA brindar apoyo logístico a las Fuerzas de Seguridad. En teoría, no debería haber problema en que, ante una situación crítica, los militares intervengan en temas de Seguridad Interna, el problema es cuando esta es transforma en su principal misión.

Algunos de los peligros que conlleva la intervención de las FFAA en temas de Seguridad doméstica son el excesivo uso de la violencia (ya que los militares no están formados para realizar tareas de Seguridad) y la posible corrupción de los militares en manos del narcotráfico. El caso de México es, en este sentido, esclarecedor, pero más grave aún es el hecho que este tipo de discusiones nos desvía del debate más amplio que propone Eissa.

También, debemos recordar que contar con FFAA preparadas para defender los "intereses vitales y estratégicos" del país no es un proceso rápido. No tanto por el tiempo 
que toma adquirir o desarrollar nuevos sistemas de armas, sino por lo difícil que resulta preparar los recursos humanos que los sistemas de defensa modernos necesitan. El peligro radica entonces en que cuando cuando una sociedad se da cuanta que necesita FFAA ya es demasiado tarde. Es por esto que los países exitosos, independientemente de cuán benigno sea el escenario intenacional en un determinado momento, cuentan con sistemas de defensa operativos.

En definitiva, la distancia entre el lugar en el que nos encontramos y en el que deberíamos estar, es tan grande que nos obliga a realizar un cambio copernicano en la manera en que entendemos la Defensa.

El autor hace bien en mencionar a los actores que conforman la comunidad de Defensa ya que algunos de ellos deberían en los próximos años liderar una reforma. Necesitamos, por ejemplo, emprendedores políticos e intelectuales capaces de generar consciencia social sobre la importancia que la Defensa tiene en el mundo moderno.

$Y$ uno de los problemas que enfrenta la Argentina es que no tiene una comunidad de expertos en temas estratégicos. Hay por supuesto especialistas que actúan de manera individual, pero no una red de instituciones capaz de pensar la Defensa y la Seguridad Internacional e influir posteriormente en la implementación de las políticas públicas.

A diferencia de lo que ocure en áreas de gobierno que despiertan gran interés en la sociedad civil y en el sector privado en particular, como puede ser la economía, los temas estratégicos necesitan del apoyo del Estado. Es por esto, que las naciones más avanzadas, además de tener sistemas de defensa operativos, colaboran económicamente con los centros de estudios y los think tanks que realizan este tipo de trabajo.

Para concluir, la Argentina necesita liderazgos intelectuales y políticos dispuestos a generar consciencia sobre temas que, si bien no figuran en las encuestas, tienen enorme importancia para el futuro del país. La defensa es uno de ellos.

Cuando estos actores domésticos no están presentes, se genera un vacío que eventualmente puede ser ocupado por las recomendaciones de otros países, sugerencias que como bien señala Eissa reflejarán sus intereses pero no necesariamente los nuestros. En definitiva, en vez de hacer lo que nos sugieren los países que admiramos, imitemos su accionar.

\section{Hipótesis}

Paso ahora a analizar las dos hipótesis que el autor presenta en el texto. La primera, sostiene que el encruzamiento de dos factores (el realismo y la "dependencia") ha tendido a paralizar el debate sobre el futuro de la Defensa en la Argentina ya que nos "arrastra" hacia el siglo XX.

En el caso del realismo, esto ocurre porque nos obliga a pensar en términos de hipótesis de conflicto con nuestros vecinos, mientras que la dependencia nos lleva a analizar la Defensa bajo esquemas que promueven la lucha contra el terrorismo islámico y el narcotráfico ( $y$ a no analizar las amenazas convencionales externas, que es en definitiva la principal tarea de la Defensa Nacional)

Mi comentario tiene que ver con la visión que Eissa presenta sobre el realismo. En el mundo actual, gran parte de los especialistas en Seguridad Internacional y prácticamente la totalidad de los practitioners piensan la Defensa (lo digan abiertamente o no) 
en términos realistas. Y lo hacen debido al éxito que esta tradición de pensamiento y gobierno ha tenido a lo largo de la historia tanto para explicar lo que ocurre en el escenario internacional como para predecir el accionar futuro de los Estados.

El realismo no es por lo tanto una teoría que deba ser asociada al pensamiento geopolítco de los militares sudamericanos de antaño, sino una forma de pensar el mundo sumamente moderna. De hecho, tanto el ex presidente Barack Obama como la reciente estrategia de defensa de EEUU se alejaron del prisma liberal o el neoconservador para volver a analizar el mundo desde el realismo. Los realistas tampoco se han limitado recientemente a pensar únicamente los conflictos convencionales entre estados, sino que también analizan el terrorismo, las guerras civiles y la ciberseguridad, entre otro tipo de conflictos.

Por lo tanto, la concepción realista puede ser utilizada para analizar prácticamente cualquier tipo de amenza y se ha mostrado asimismo capaz de adaptarse a los contínuos cambios que tienen lugar en el escenario internacional. Es por esto que ningún verdadero realista pensaría la relación actual de la Argentina con Chile y Brasil, de la forma en que lo hubiese hecho algunas décadas atrás.

El realismo es entonces un primer marco teórico que puede ayudarnos a entender la Defensa. Eso no significa que no exista lugar para otro tipo de enfoques (Derechos Humanos, estudio de género, relaciones cívico-militares, por ejemplo), sólo que el realismo y su pesimismo sobre la naturaleza humana, junto con su visión sobre el rol que la anarquía juega en el Sistema Internacional, siguen siendo un conjunto de teorías sumamente valioso para entender el pasado, el presente y el futuro.

La segunda hipótesis de Eissa, señala a la continua rotación de los miembros en el Poder Legislativo de la Argentina puede explicar su falta de interés por temas que afectan el bienestar del pais en el largo plazo, como es el caso de la Defensa. Creo que este factor tiene un rol pero ciertamente este no es central.

Si observamos la experiencia de países con políticas de defensa exitosas, encontraremos muchos que tienen sistemas políticos similares al nuestro. Esto sucede por ejemplo en el caso de EEUU pero también en el de Chile. Eissa anticipa esta réplica y señala que los representantes estadounidenses tienen mayor continuidad en sus cargos porque renuevan sus bancas de manera regular. Si bien esto es cierto, no considera que los diputados de EEUU viven en contínua campaña ya que renuevan sus bancas cada dos años. Los incentivos los llevan, por lo tanto, a pensar en el corto plazo y a focalizarse en temas que afectan la vida diaria de sus electores. ${ }^{2}$

Si uno estudia la experiencia argentina también verá que a principios del XX, nuestro país tenía un sistema político similar al actual (al menos en términos de renovación de bancas) y al mismo tiempo poseía un sistema de Defensa eficiente y moderno.

El problema de fondo, radica en que una parte significativa de la dirigencia argentina no tiene una clara visión de país a largo plazo y, por lo tanto, no están interesados por los temas estratégicos. Este es un mal que no afecta solamenete a los legisladores, sino

\footnotetext{
${ }^{2}$ Podríamos inclusive pensar que el sistema de Estados Unidos es peor que el argentino en términos de incentivos, ya que sus legisladores responden a los electores de pequeños distritos y no forman parte de listas nacionales. Por lo tanto, el grado de control que los votantes pueden ejercer sobre sus representantes es mayor, lo cual nos hace suponer que los temas cotidianos deberían prevalecer sobre los estratégicos.
} 
también a los miembros de los otros dos poderes del Estado, a los empesarios, a los intelectuales y a los periodistas, entre tantos otros. Esto no hace más que recordarnos lo importante que sería para el país contar con nuevos emprendedores políticos e intelectuales que transmitan ideas, inspiren, convenzan y logren alinear los intereses de los distintos actores para modernizar nuestras FFAA.

\section{Próximos pasos}

Las reformas de cuarta generación que propone el autor (sistema de ingresos al ministerio de defensa, modificar el despliegue actual de las fuerzas, incrementar el presupuesto militar, etc.) son sumamente valiosas pero dejan de lado las de primera, segunda y tercera generación. Efectivamente, dado el grado de abandono en el que se encuentra nuestro sistema de Defensa debemos comenzar a pensarlo de nuevo (lo cual no deja de ser una ventaja)

Si bien Eissa, no considera necesario cambiar las leyes existentes, creo que debemos pensar en la posibildad de discutir una nueva ley de Defensa Nacional. Quizás esto no sea necesario desde el punto de vista jurídico pero sí lo es en términos políticos. Los argentinos nos debemos un gran debate nacional y una discusión parlamentaria puede ser la mejor forma de tenerlo.

Otra ventaja de esta estrategia es que, a diferencia de la posible modernización de nuestros sistemas de armas, no requiere de un aumento del gasto público en los próximos dos años, algo que dada la situación fiscal en la que se encuentra el país resulta altamente improbable.

Menciono algunos temas para discutir. El primero, tiene que ver con la definición de los principales escenarios estratégicos del país. Creo que, debida a la presencia de las Islas Malvinas y la relevancia estratégica que viene ganando la Antártida, el Atlántico Sur es clave. Esto tiene importantes implicancias en términos de organización de las Fuerzas, ya que la Armada debería ganar mayor protagonismo del que ha tenido hasta ahora. Pero la ventaja de adoptar un esquema de escenarios geográficos no es sólo práctica, sino también teórica. El planeamento por capacidades es un proceso demasiado abstracto $y$, por lo tanto, debe ser acotado. Más aún en el caso e un país mediano que, a diferencia de EEUU, no afronta un sinnúmero de amenazas.

Relacionado con el rol de la Armada, ¿tiene sentido eliminar su brazo áereo? Por más que no tengamos portaaviones, los aviones que operan sobre el mar son diferentes a los que lo hacen sobre la tierra. Los pilotos necesitan asimismo un entrenamiento diferente. Sin ir más lejos, recordemos las imágenes de las bombas que en Malvinas, lanzadas a buques británicos desde nuestros aviones de la Fuerza Aerea, atravesaron las cubiertas sin explotar. Otro punto clave es la formación del cuerpo de oficiales. Este es un proceso que lleva décadas y, por lo tanto, debe ser priorizado. Esto no significa que la educación de los suboficiales, los soldados y las reservas no sea importante, tan sólo que un país que carece de recursos debe priorizar.

Otro debate que nos debemos es la manera en que vamos a modernizar nuestros sistemas de armas. Al fin y al cabo, este es un tema que domina los debates sobre Defensa en prácticamente todos los países, incluyendo en Brasil y Chile. Esta es la esencia de la Defensa. 
¿Qué sistemas de armas serán comprados en el exterior, cuales serán producidos en el país con tecnología y diseño de otros países y, finalmente, cuales serán producidos integramente en la Argentina?

Existen muy pocos estados que actualmente tienen la capacidad para producir aviones de combate. Inclusive un país con la industria militar que tiene Israel abandonó esta idea décadas atrás. La Argentina debería por lo tanto adquirir aviones de combate de cuarta generación en el exterior.

La Argentina necesita asimismo retomar la tradición de construir en el país submarinos con tecnología alemana (o, como alternativa, francesa). Dado el tamaño de nuestro mar y la importancia que esta ganando la Antártida, necesitamos al menos cuatro modernos submarinos.

Finalmente, no debemos dejar de mencionar el desarrollo doméstico de algunas tecnologías sensibles. Esto es importante no solamente porque nos da mayor autonomía, sino también porque las naciones avanzadas son reacias a brindarlas. Asimismo, estas tecnologías benefician a toda la economía debido a las externalidades positivas que producen. En este sentido, el INVAP es un ejemplo a imitar.

Las ventajas comparativas que la Argentina tiene en las industrias tecnológicas y de software (recordemos que somos el país latinoamericano con mayor cantidad de unicornios) pueden asimismo servirnos de base para desarrollar una industria de ciberseguridad que sea competitiva a nivel internacional. 